\title{
Empreendedorismo: Um Estudo de Caso sobre o perfil empreendedor no setor couro calçadista em Campina Grande - PB
}

\author{
Entrepreneurship: A Case Study on the entrepreneur profile in the leather-footwear \\ sector in Campina Grande - PB \\ Recebido em 24.07.2013. Aprovado em 23.10. 2013 \\ Avaliado pelo sistema double blind review
}

Erika Felix Azevedo

adm.erikafelix@gmail.com

Faculdade Mauricio de Nassau -CG

\section{Resumo}

Em momentos de crise o empreendedorismo apresenta-se como sendo vital para o fortalecimento da economia nacional, especialmente no Brasil, onde a população apresenta natureza empreendedora. Estado da Paraíba é historicamente conhecido como sendo uma região produtora de calçados, atividade de grande destaque para a ocupação de uma mão de obra disponível e abundante principalmente em Patos, Campina Grande e João Pessoa, as maiores cidades do estado. A presente pesquisa justifica-se pelo inegável valor do setor couro calçadista para a economia da cidade, sendo esta uma área que ocupa grande número de mão-de-obra disponível, gerando consequentemente emprego e renda. Evidencia-se ainda a importância desta discussão em torno do fenômeno empreendedorismo, sobretudo para a área acadêmica, ao buscar estudar 0 empreendedorismo no setor couro calçadista de Campina Grande/PB e suas peculiaridades, motivações, dificuldades, trazendo informações relevantes que possam contribuir com o surgimento de negócios bem sucedidos no setor, alavancando a economia regional de forma sustentável. Diante do exposto, pesquisa buscará averiguar a influência da personalidade empreendedora para o desenvolvimento do setor couro calçadista na cidade de Campina Grande/PB. A pesquisa é classificada como sendo descritiva, bibliográfica e de campo. Descritiva, pois visa analisar o perfil empreendedor dos empresários do ramo couro calçadista da cidade de Campina Grande. Bibliográfica, pois para a fundamentação teórico metodológica do trabalho serão utilizados materiais publicados em livros, artigos e redes eletrônicas. Considera-se ainda como sendo pesquisa de campo, pois dados primários serão coletados por meio de um questionário estruturado nas micro e pequenas empresas situadas em Campina Grande que atuam no setor couro calçadista.

Palavras-chave: Empreendedorismo; Perfil empreendedor; Desenvolvimento econômico; Setor couro calçadista.

\begin{abstract}
In times of crisis, entrepreneurship is considered essential to strengthen the national economy, especially in Brazil, where the population has entrepreneurial nature. The state of Paraiba is historically known as a shoeproducing region, activity with great emphasis on the occupation of available labor and common mainly in Patos, Campina Grande and João Pessoa, the largest cities in the state. This research is justified by the undeniable value of leather-footwear sector for the economy of the city, as it is an area that holds large numbers of available labor, thereby generating employment and income. It is also evident the importance of this discussion on entrepreneurship phenomenon, especially in the academic area, by seeking to study entrepreneurship related to leather-footwear sector in Campina Grande / PB and its peculiarities, motivations and hardships, bringing up relevant information that may contribute to the emergence of successful businesses in the sector, boosting the regional economy in a sustainable way. Thus, this study aims to investigate the influence of the entrepreneurial personality for the development of the leather-footwear sector in Campina Grande / PB. It's a descriptive, bibliographical and field research. It's considered descriptive as it aims to analyze the profile of the entrepreneur in the leather-footwear section in Campina Grande; bibliographical - once that information published in books, articles and electronic networks will be used for the basis of the theoretical work; and it is also classified as a field
\end{abstract}


research, because primary data will be collected through a structured questionnaire on micro and small enterprises in Campina Grande which work in leather-footwear sector.

Keywords: Entrepreneurship, Entrepreneur Profile; Economic Development; leather-footwear sector.

\section{Introdução e objetivos}

Segundo Machado et al (2010), os dados fornecidos pelo Global Entrepreneurship Monitor que avaliam o nível de atividade empreendedora no mundo desde 1999 revelam que o empreendedorismo nacional não se abalou em 2009 e houve uma aceleração do empreendedorismo por necessidade em decorrência do aumento do desemprego, em detrimento do empreendedorismo por oportunidade, relativo aos empreendedores que possuem vocação ou enxergam nichos de mercado.

Em momentos de crise, como o ocorrido em 2009 no mundo, o empreendedorismo se mostrou essencial para 0 fortalecimento da economia nacional.

Degen (2009) argumenta que para o futuro empreendedor, a crise representa oportunidades para iniciar seu negócio explorando as novas tendências do mercado global, contudo para o empresário estabelecido, a crise representa em primeiro lugar, ameaças aos seus negócios se eles estiverem explorando tendências declinantes do mercado.

Ressalta-se então a importância do empreendedorismo em momentos de crise, sobretudo sobre o emprego, especialmente no Brasil, onde a população apresenta uma natureza empreendedora.

O Empreendedorismo é um tema de relevante importância no Brasil, estando relacionado com a influência que as pequenas empresas exercem na economia do mundo atual. Além disso, é notória a existência de oportunidades no ambiente para novos negócios e clima econômico favorável.

Conforme dados do GEM em Machado (2010), observa-se que o Brasil em um grupo composto por 22 países, tem a sexta maior taxa de TEA (15,3\%), ou seja, taxa de empreendedores iniciais. A TEA é a proporção de pessoas com idade entre 18 e 64 anos envolvidas em atividades empreendedoras na condição de empreendedores de negócios nascentes ou empreendedores à frente de negócios novos, com menos de 42 meses de existência. O Brasil apresenta ainda uma diferença significativa em relação a todos os países europeus. Vale salientar que os empreendimentos são em sua maioria voltados para os consumidores finais, representando $(70,9 \%)$, superando a média registrada entre os países de menor desenvolvimento econômico, sendo os que se direcionam para esse setor.

Conforme Moutinho (2003), o Estado da Paraíba é historicamente conhecido como sendo uma região produtora de calçados, atividade de grande destaque para a ocupação de uma mão de obra disponível e abundante principalmente em Patos, Campina Grande e João Pessoa, as maiores cidades do estado. É inegável que as alternativas de ocupação da mão de obra nessas cidades são bem maiores do que nos pequenos municípios da circunvizinhança.

Na cidade de Campina Grande, maior pólo calçadista do Nordeste e $5^{\circ}$ do Brasil, com 450 empresas formais e informais, com produção em torno de 160 mil pares/ano, encontra-se o centro de couro calçadista "Manoel Raimundo Souto", localizado no bairro de Bodocongó, representando um investimento de cerca de R $\$ 5$ milhões, inaugurado em 2007 pelo ex governador Cássio Cunha Lima. Compreende as empresas: Calçados Donna, Milleny, Adriana, Florêncio e Montenegro. Tais empresas proporcionam para a região geração de empregos e renda, beneficiando mais de 1500 pessoas. Contando com o apoio do centro de excelência especializado: Centro de Tecnologia de Couro e do Calçado Albano Franco, com parceria com SEBRAE e do Sindicalçados realizando o Projeto Setorial Integrado (PSI) com objetivo de internacionalizar as empresas.

Justifica-se a importância desta atividade para a região por se tratar de uma tradição cultural nordestina, pois desde o século XVI havia a produção artesanal desde produtos domésticos a calçados, sendo esta atividade acelerada a partir do século XVIII com o "ciclo do gado". O couro foi um dos primeiros produtos a ser exportado 


\title{
Empreendedorismo: Um Estudo de Caso sobre o perfil empreendedor no setor couro calçadista em Campina Grande - PB
}

pelos portugueses, e atingiu o estágio industrial exatamente na cidade de Campina Grande. Outro fator de grande importância que justifica a presente pesquisa é o inegável valor do setor para a economia da cidade por esta ser uma área ocupa grande número de mão-de-obra disponível, gerando consequentemente emprego e renda.

Neste sentido McClelland (1987, p. 232) assegura:

\begin{abstract}
Não tem uma forma melhor de prover a base para o rápido crescimento econômico do que incrementar dramaticamente 0 número de empreendedores ativos na sociedade. Eles representam um segmento pequeno da população, mas seu impacto é crucial, pois obtêm recursos para produzir bens e serviços, criar empregos e diminuir a dependência do governo.
\end{abstract}

Diante do exposto, evidencia-se a importância desta discussão em torno do fenômeno empreendedorismo, sobretudo para a área acadêmica, ao buscar estudar o empreendedorismo no setor couro calçadista de Campina Grande/PB e suas peculiaridades, motivações, dificuldades, trazendo informações relevantes que possam contribuir com o surgimento de negócios bem sucedidos no setor, alavancando a economia regional de forma sustentável.

Deste modo, a pesquisa buscará averiguar a influência da personalidade empreendedora para 0 desenvolvimento do setor couro calçadista na cidade de Campina Grande/PB. Para atingir o objetivo proposto pretende-se:

- Expandir a compreensão sobre o empreendedorismo na cidade de Campina Grande/PB;

- Analisar os conceitos acerca do perfil empreendedor, avaliando características e/ou traços de personalidade empreendedora sob o ponto de vista de diversos autores;

- Examinar traços de personalidade empreendedora nos empresários do setor couro calçadista de Campina Grande/PB;

- Identificar as principais dificuldades vivenciadas pelos empreendedores em Campina Grande/PB;

- Investigar as principais motivações dos empreendedores do ramo calçadista para iniciar a atividade empreendedora.

\section{Referencial Teórico}

\section{Conceituando Empreendedorismo}

Empreendedor é uma palavra que vem do latim imprendere, que para Houaiss, (2001) que dizer: "decidir realizar tarefa difícil e laboriosa", para Ferreira (2000) significa "colocar em execução". Tem o mesmo significado da palavra francesa entrepreneur, dando origem a palavra inglesa entrepreneurship, sendo a mesma utilizada para designar o comportamento do empreendedor, ou seja, o "espírito empreendedor".

O primeiro exemplo de empreendedorismo foi representado por Marco Polo, com a tentativa de estabelecer uma rota comercial no Oriente, assinando um contrato com um homem de posses para vender as mercadorias do mesmo. Enquanto ele vendia a mercadoria e corria todos os riscos, o homem "capitalista" assumia o papel de investidor.

$\mathrm{Na}$ idade média, o termo empreendedor foi utilizado para definir aquele que gerenciava grandes projetos de produção. Esse indivíduo não assumia grandes riscos, e apenas gerenciava os projetos, utilizando os recursos disponiveis, geralmente provenientes do governo do país (MAXIMIANO, 2006).

De acordo com Dornelas (2005), no século XVII os primeiros indícios de relação entre assumir riscos e empreendedorismo ocorreram nessa época, em que o empreendedor estabelecia um acordo contratual com 0 
governo para realizar algum serviço ou fornecer produtos. Como geralmente os preços eram prefixados, qualquer lucro ou prejuízo era exclusivo do empreendedor. Richard Cantillon, importante escritor e economista do século XVII, é considerado por alguns como sendo um dos criadores do termo empreendedorismo, sendo um dos primeiros a diferenciar 0 empreendedor (aquele que assume riscos), do capitalista (aquele que fornece 0 capital). Ainda segundo Dornelas (2005), no século XVIII, o capitalista e o empreendedor foram finalmente diferenciados, provavelmente devido ao início da industrialização que ocorria no mundo. Como a eletricidade, a química de Thomas Edison, financiadas por investidores. No final do século XIX e início do século XX, os empreendedores foram frequentemente confundidos com os gerentes ou administradores (o que ocorre até os dias atuais), sendo analisados meramente de um ponto de vista econômico, como aqueles que organizam a empresa, pagam os empregados, planejam, dirigem, controlam as ações desenvolvidas na organização, mas sempre a serviço do capitalista. Entre diferenças e semelhanças entre administrador e empreendedor, um complementa o outro, entretanto nem todo administrador é um bom empreendedor de sucesso, tendo características e atitudes que o diferenciam do administrador tradicional.

O empreendedorismo não é um assunto tão recente e vem sendo definido por diversos autores. Para Schumpeter (1949), o empreendedor é aquele que destrói a ordem econômica existente pela introdução de novos produtos e serviços, pela criação de novas formas de organização ou pela exploração de novos recursos e materiais, mas não se limita a isso. Na visão de Timmons (1994), o empreendedorismo trata-se de uma revolução silenciosa, que será para o século XXI mais do que a revolução industrial foi para o século XX. Para Baron e Shane (2011), Empreendedorismo é um processo - uma cadeia de eventos e atividades que ocorrem ao longo do tempo - em alguns casos, períodos consideráveis de tempo. Ele começa com uma ideia para algo novo - muitas vezes, um novo produto ou serviço. Para Dornelas (s.d.), o momento atual pode ser chamado de a era do empreendedorismo, pois são os empreendedores que estão eliminando barreiras comerciais e culturais, encurtando distâncias, globalizando e renovando os conceitos econômicos, criando novas relações de trabalho e novos empregos, quebrando paradigmas e gerando riqueza para a sociedade.

Silva (2009) ressalta que o empreendedorismo deve ser observado, enquanto processo dinâmico que tem inerente a concepção, percepção e a realização de uma oportunidade de negócio, tem o pressuposto do envolvimento de pessoas e processos e que, em conjunto, fazem a transformação de ideias em oportunidades.

Portanto, pode-se dizer que "empreender é encontrar a sua luz entre tantas outras, e o mais importante, fazê-la permanecer brilhando".

\section{Perfil distintivo do empreendedor}

Diante das diversas percepções de vários autores sobre o perfil distintivo do empreendedor, percebe-se que há certa convergência no sentido de perceber no empreendedor características diferenciadas. São várias as formas de caracterizar o empreendedor. Para Gerber (2004), o empreendedor é um estrategista, que cria métodos inéditos para a geração de oportunidades em mercados, transformando possibilidades em probabilidades. $E$, nessa linha, sua ação tem impacto decisivo em contextos organizacionais, já que seu dinamismo praticamente dita o ritmo de andamento dos processos. Para Filion (1991), um empreendedor é uma pessoa que imagina, desenvolve e realiza visões. De acordo com Azevedo (1992), o Empreendedor é aquele indivíduo que tem necessidade e é capaz de desenvolver novos projetos. (...) é aquele que assume a responsabilidade de conduzir um negócio próprio, de tal forma que esse empreendimento funcione e alcance o sucesso. Para Dornelas (2001), em qualquer definição sobre empreendedorismo encontram-se, no mínimo, os seguintes aspectos referentes ao empreendedor: Iniciativa para criar um novo negócio e paixão pelo que faz; utilização dos recursos disponíveis de forma criativa transformando o ambiente social e econômico onde vive; e aceita assumir riscos e a possibilidade de fracassar.

Qualquer que seja a definição do empreendedorismo percebe-se que alguns aspectos são relevantes: os empreendedores são antes de tudo corajosos, tem criatividade, amam o que fazem, tem visão de futuro, sem deixar de calcular os riscos, sem esquecer que são muito persistentes e ousados, não desistindo facilmente. Todas essas definições compõem o perfil do empreendedor.

Para Maximiano (2006), o perfil empreendedor é considerado por uma perspectiva comportamental, traços que se combinam e se manifestam de diferentes maneiras e em diferentes graus de intensidade, em diferentes 


\section{Empreendedorismo: Um Estudo de Caso sobre o perfil empreendedor no setor couro calçadista em Campina Grande - PB}

pessoas, integrando assim as competências que todo empreendedor deve ter, como: criatividade e capacidade implementação, disposição para assumir riscos, perseverança e otimismo e senso de independência. Segundo Dornelas (2005), até pouco tempo, muitos acreditavam que o espírito empreendedor era algo inato, que os vencedores já nasciam com um diferencial e eram predestinados ao sucesso nos negócios. Recentemente, cada vez mais, a literatura traz resultados de pesquisas que apontam no sentido de que o comportamento dos empreendedores bem-sucedidos pode ser ensinado e compreendido, em boa medida, por qualquer pessoa.

O psicólogo americano David McClelland realizou uma pesquisa mundial em 1960, sobre as características empreendedoras e concluiu que pessoas bem sucedidas materialmente eram aquelas que possuíam como motivação principal a busca da realização e êxito e, neste sentido desenvolvem comportamentos que as levam ao sucesso. A partir dos trabalhos publicados por McClelland e Winter em 1971 e McClelland em 1972, o PNUD - Programa das Nações Unidas para o Desenvolvimento - desenvolveu um programa experimental para capacitação de empreendedores em 1985, que foi lançado oficialmente, após aperfeiçoamentos, em 1988.

0 projeto identificou as dez principais características do comportamento empreendedor, comuns aos empreendedores bem-sucedidos. O Quadro 1 apresenta tais características, divididas em três conjuntos distintos:

Quadro 1 - Características Empreendedoras

\begin{tabular}{|c|c|c|}
\hline Conjunto de realização & Conjunto de poder & Conjunto de planejamento \\
\hline Busca de oportunidade e iniciativa & $\begin{array}{l}\text { Independência e } \\
\text { autoconfiança }\end{array}$ & Busca de informações \\
\hline Persistência & \multirow{4}{*}{$\begin{array}{l}\text { Persuasão e rede de } \\
\text { Contatos }\end{array}$} & Estabelecimento de metas \\
\hline Correr riscos calculados & & \multirow{3}{*}{$\begin{array}{l}\text { Planejamento e monitoramento } \\
\text { sistemático }\end{array}$} \\
\hline Exigência de qualidade e eficiência & & \\
\hline Comprometimento & & \\
\hline
\end{tabular}

Fonte: adaptado a partir de SEBRAE (1998).

Atualmente, o programa é chamado EMPRETEC, sendo executado pelo Sistema Sebrae, em parceria com o PNUD dirigido a empresários e futuros empreendedores e tem por objetivo identificar e aumentar o potencial empresarial empreendedor do participante e já é aplicado em mais de 27 países, sendo o Brasil uma referência no desenvolvimento do programa.

O EMPRETEC baseia-se no fato de que o sucesso empresarial não é conseqüência apenas da habilidade dos empreendedores para gerenciamento dos negócios ou de condições favoráveis estabelecidas por política governamental. Dependendo muito do comportamento do indivíduo, apoiando-se na crença de que existem características e comportamentos pessoais que são comuns aos empresários bem-sucedidos. Não se trata de um curso convencional e sim de uma metodologia de base vivencial, de alto impacto, voltada para resultados (SEBRAE, 2010).

\section{Identificando as Oportunidades}

Baron (2011) percebe o empreendedorismo como um processo, onde os empreendedores se envolvem nas atividades, sendo fundamental considerar as condições econômicas, tecnológicas e sociais das quais as oportunidades surgem, as pessoas que reconhecem essas oportunidades (empreendedores), as técnicas de negócios e estruturas jurídicas que elas usam para desenvolvê-las e os efeitos sociais e econômicos produzidos por tal desenvolvimento.

O empreendedorismo é um processo que se desenvolve ao longo do tempo se move por meio de fases distintas, mas intimamente relacionadas. As principais fases do processo para Baron (2011) são as seguintes: 


\section{Erika Felix Azevedo}

- Reconhecimento de uma oportunidade - As oportunidades têm o potencial de gerar valor econômico e são vistas como desejáveis na sociedade em que ocorrem, em suma são geradas por fatores econômicos, tecnológicos e sociais.

- Decidir ir em frente e reunir os recursos iniciais - Os futuros empreendedores descobrem que devem reunir informações básicas, (sobre mercados, questão ambiental e jurídica), recursos humanos (sócios, funcionários) e recursos financeiros.

- Lançar um novo empreendimento - Após a reunião dos recursos necessários deve-se pensar no modelo do formato jurídico do empreendimento, desenvolver o novo produto ou serviço, definir os papéis da equipe e da alta administração, etc.

- Construir com Sucesso - Administrar o novo empreendimento e transformá-lo em um negócio lucrativo, para isso é necessário reconhecer a importância dos recursos humanos, nenhuma empresa cresce sem funcionários talentosos e motivados, esta fase do processo é crucial para atrair essa mão de obra e fazer com que permaneçam na empresa.

- Colher as Recompensas - Nesta última fase os empreendedores devem escolher cuidadosamente uma estratégia que lhes permita maximizar os benefícios obtidos pelo seu tempo, esforço e talento.

Baron (2011) salienta que a história chama atenção para grandes empreendedores como: Jonh D. Rockefeller, Andrew Carnegie e Cornelius Vanderbilt, que conseguiram acumular grandes fortunas com seus empreendimentos, fazendo com que as pessoas fiquem entusiasmadas. Com ajuda da mídia, que mostra casos de sucesso como, Michael Dell, Bill Gates e Mary Kay Ash, atraindo olhares para os empreendedores, sendo considerados os novos heróis e heroínas.

Outro fator é a questão do vínculo empregatício, em razão de tantos cortes no quadro de funcionários, ele foram perdendo a fidelidade ao seu empregador, buscando assim ser seu próprio patrão. E por último e não menos importante, é a mudança nos valores básicos, agora quem entra no mercado de trabalho, jovens em especial, preferem uma vida mais independente, com possibilidades de escolha em vez de certeza e previsibilidade. Esse fatores foram observados por conta o crescimento de empreendedores e o grande número de empresas que vêm sendo criadas.

Baron (2011) ressalta ainda que alguns pesquisadores explicam a existências de oportunidades de duas maneiras. Israel Kirzner, um economista da New York University, explica que as oportunidades existem porque as pessoas dispõem de informações diferentes, tornando-as melhores que as outras no processo de tomada de decisão. Em contra partida Josef Schumpeter, um economista que lecionou em Harvard University, argumentou que oportunidades empreendedoras realmente valiosas provêm de uma mudança externa que torna possível fazer algo novo que ainda não havia sido feito, ou fazer algo de uma forma mais valiosa. Pesquisadores que seguiram esses princípios identificaram três fontes principais de oportunidade: mudança tecnológica, mudança política ou de regulamentos, e mudança social e demográfica. Os empreendedores podem desenvolver idéias de negócios para tirar vantagem de cinco diferentes tipos de oportunidades que resultam dessas mudanças, são elas: oportunidades em novos produtos e serviços, novos métodos de produção, novos mercados, novas formas de organização e novas matérias-primas.

\section{Empreendedorismo no Brasil}

O Empreendedorismo tem sido muito difundido no Brasil, principalmente na década de 1990, existem diversos fatores que justificam esse avanço repentino, além dos incentivos por parte do governo e de entidades de classe. Um dos motivos foi o aumento do índice de desemprego, principalmente nas grandes cidades, onde a concentração de empresas é maior, assim tiveram a necessidade de criar seus próprios negócios, mesmo sem experiência no ramo e com pouco dinheiro, muitos permanecem na economia informal, por falta de credito, excesso de impostos e altas taxas de juros. Atualmente temos os novos negócios, movidos pela nova economia globalizada, são os que nascem na Internet, entre os anos 1999 e 2000, e a cada ano vem se aperfeiçoando. Sem esquecer também dos que herdam as empresas dos pais ou parentes e que dão continuidade. Dados do SEBRAE mostram que no Brasil somam-se $99,2 \%$ do conjunto de micro e pequenas empresas e apenas $0,3 \%$ são de grande porte. Por não apresentarem um planejamento reflete diretamente no alto índice de mortalidade dessas pequenas empresas. 


\section{Empreendedorismo: Um Estudo de Caso sobre o perfil empreendedor no setor couro calçadista em Campina Grande - PB}

Os incentivos no Brasil começaram no fim da década de 90 com o apoio do SEBRAE (Serviço de Apoio as Micro e Pequenas Empresas) e da Softex (Sociedade Brasileira de Apoio as Micro e Pequenas Empresas). O Sebrae tem como objetivo auxiliar o empreendedor no seu pequeno negócio, dando todo suporte para o mesmo iniciar sua empresa, além de oferecer consultoria a fim de resolver problemas que possam vir a prejudicar o futuro do seu negócio. Já a softex tem uma história interligada com o empreendedorismo brasileiro, foi criada para levar as empresas de software ao mercado externo, por meio de várias ações que proporcionavam ao empresário de informática a capacitação em gestão e tecnologia.

O tema começou a ser despertado na sociedade a partir de programas criados pela softex em todo país, junto a incubadoras de empresas e a universidade de ciências da computação, após 15 anos de amadurecimento do assunto, o país tem um grande potencial para desenvolver programas de ensino de empreendedorismo de todo o mundo, comparável apenas aos Estados Unidos, onde há mais de 1500 escolas que ensinam empreendedorismo. Alguns programas que apoiam e desenvolvem o empreendedorismo:

- Os programas Softex e GENESIS, apoiam atividades de empreendedorismo em software;

- EMPRECTEC, programa desenvolvido pelo SEBRAE para capacitação do empreendedor;

- Cursos e Programas criados nas Universidades brasileiras para o ensino do empreendedorismo. Por exemplo: Engenheiro empreendedor (Santa Catarina), Ensino Universitário de Empreendedorismo, da CNI (Confederação Nacional das Indústrias) e IEL (Instituto Euvaldo Lodi). Além de programas específicos por escolas de Administração de empresas e de tecnologia para formação de empreendedores, incluindo cursos de MBA e cursos específicos de curta e média duração.

- Anprotec (Associação Nacional de Entidades Promotoras de Empreendimentos de Tecnologias Avançadas) são incubadoras de empresas que geram postos de trabalho em todo país.

- Empreendedor Individual

Para que qualquer negócio não funcione exclusivamente no papel e saia apenas dos sonhos, é necessário que haja um financiamento. No Brasil existem algumas entidades oferecem várias fontes de financiamento:

- Economia Pessoal, Família, Amigos, são os tipos mais comuns de financiamento, conseguido através de fatores pessoais e do ambiente que cerca o empreendedor, valendo-se da amizade e confiança que as pessoas têm no empreendedor e a credibilidade que o mesmo inspira.

- Angel Investir (Investidor "Anjo") é um investidor pessoa física, um capitalista que possui dinheiro e busca alternativas para obter melhor rentabilidade para esse dinheiro. Ele coloca o "dinheiro semente inicial" para a criação de muitos negócios, mas para que isso ocorra ele analisa muito bem o plano de negócio e o seu potencial e em troca desse dinheiro ele torna-se um acionista da empresa ou de uma quota do seu capital social.

Além de algumas fontes provenientes dos governos municipais, estaduais e federais, muitas vezes com custos bem baixos:

- Programa RHAE (Programa de Capacitação de Recursos Humanos para Atividades Estratégicas) é uma iniciativa do Ministério da Ciência e Tecnologia, com o objetivo de dotar o país de melhores condições de competitividade no mercado mundial, por meio da capacitação de recursos humanos.

- Microcrédito é uma forma recente de apoio aos pequenos empreendimentos, oferecendo menores quantias a juros mais acessíveis, apoiando também negócios informais.

- Projeto Inovar-Capital de Risco Brasil, idealizado pela Finep, "visa construir um ambiente institucional que favoreça o florescimento da atividade de capital de risco no Brasil, de forma a estimular o fortalecimento das empresas nascentes e emergentes de base tecnológica brasileira, contribuindo, em última instancia, para o desenvolvimento tecnológico nacional, bem como para a geração de empregos e renda". A incubadora do fundo Inovar é um consórcio entre Finep, Sebrae, Fumin, BID e Petros.

Para Machado et al (2010), o Brasil, mesmo tendo aumentado sua taxa de TEA, decaiu uma posição no ranking de empreendedorismo: era $13^{\circ} \mathrm{em} 2008$ e $14^{\circ} \mathrm{em} 2009$. Isso se explica pelo simples fato da entrada de novos países em 2009, com taxas superiores a brasileira, ou seja, como o conjunto de países varia ano a ano, a

CGE * v .1 * n. 1 * Jan-Abr 2013 * 96-105 
avaliação segundo rankings deve ser feita com as devidas ressalvas devido a essa característica da pesquisa. 0 autor acrescenta ainda que o empreendedorismo no Brasil e demasiadamente marcado por empreendimentos até certo ponto rudimentar, com foco em serviços orientados ao consumidor final. Mais uma vez, destacam-se 0 segmento de comércio de produtos alimentícios e confeç̧ões. E importante chamar a atenção para o fato de que esse perfil de empreendimentos baseados no atendimento direto ao consumidor final possui forte propensão à informalidade, baixa necessidade de recursos financeiros para a abertura do negócio e poucas exigências em termos de complexidade organizacional.

\section{Empreendedorismo no Setor Couro Calçado em Campina Grande - PB}

Vários estados iniciaram o processo de fabricação de calçados em escala industrial no Brasil a partir da segunda metade do século passado e um desses estados foi à Paraíba. Graças a sua vocação "coureira" e de algodão, tais produtos conseguiram se inserir em mercados brasileiros e nas economias mais avançadas do mundo. No estado da Paraíba as cidades que se destacam na produção de calçados são as de João Pessoa, Campina Grande e Patos.

O surgimento da atividade coureira de Campina Grande iniciou-se no ano de 1923 com a criação de Curtumes na cidade, fruto da iniciativa pioneira da família Motta, quando a cidade possuía cerca de 4000 habitantes (ALBUQUERQUE, 1998). A vocação coureira e a posição geográfica privilegiada entre o sertão e a cidade do Recife-PE, fizeram com que Campina Grande se constituísse em um dos principais centros produtores de calçados do Brasil e o principal da região Nordeste.

A produção do couro de Campina Grande teve seu período de apogeu entre 1940-1954, sobretudo na Segunda Grande Guerra, quando exportavam seus produtos. Nas décadas de 60 e 70 a indústria coureira entra em processo de declínio reduzindo o número de curtumes à metade, fato atribuído principalmente ao acirramento da concorrência com o Rio Grande do Sul. É também a partir deste período que as atividades de produção de calçados iniciam seu crescimento. Apesar do seu declínio nos anos 70, Campina Grande ainda mostrou-se ser de relevada importância para o setor.

Atualmente, o arranjo coureiro-calçadista de Campina Grande é composto fundamentalmente por produtores locais de micro, pequeno a médio porte de calçados e artefatos de couro ou de material sintético, sendo grande parte das empresas é de estrutura familiar. Ressalta-se, ainda, a entrada de empresas de fora do arranjo, mais especificamente das regiões Sudeste e Sul, a partir da década de 1980.

O Estado que mais produz calçados sintéticos no Brasil é a Paraíba, onde Campina Grande bate o recorde nacional na fabricação de sandálias desse material. O potencial robusto instigou os empresários do setor, que ampliaram sua capacidade produtiva este ano também para os produtos com valor agregado, como o calçado feminino de couro. Esse diferencial causou, em um ano, o aumento de 16\% na exportação de calçados.

O estado comercializou para o exterior nos primeiros sete meses desse ano mais de 14,1 milhões de pares de calçados, 0 valor comercializado, em média registrou uma alta de $41,26 \%$ em relação à média do mesmo período do ano passado. O par subiu de US\$2,97, para US $\$ 3,64$ de acordo com presidente do Sindicalçados, Eduardo Almeida, o Estado ocupa o segundo lugar no Brasil no ranking dos negócios internacionais. Isso se deve ao pacote de incentivos anunciados recentemente pelo Governo Federal, como a redução do IPI e do prazo para devolução dos créditos do PIS-Pasep/Cofins devem impulsionar ainda mais o setor de calçados no Estado.

A Paraíba é um Estado evolutivo na exportação de calçados. 0 setor tem parcerias para o empreendedorismo. "De acordo com dados da Abicalçados, em 2011, houve um aumento de divisas de 17,4\%. O faturamento, a Paraíba fechou esses sete primeiros meses com US\$ 51,7milhões, que corresponde a uma diferença de US\$ 7,6 milhões comparados ao mesmo período no ano passado. No ranking brasileiro, a Paraíba é o segundo em volume embarcado e o seu faturamento supera as exportações do Rio Grande do Sul (13,9 milhões de pares), ficando atrás apenas do Ceará, com 24,8 milhões de pares exportados.", disse a gestora do projeto de Calçados do Sebrae, Éricka Vasconcelos. 


\section{Empreendedorismo: Um Estudo de Caso sobre o perfil empreendedor no setor couro calçadista em Campina Grande - PB}

Há ainda no setor importantes instituições que amparam as atividades de desenvolvimento e apoio à inovação. Dentre as mais importantes instituições merecem destaque o SENAI, o SEBRAE e a Universidade Federal de Campina Grande - UFCG que mantém, em parceria com o SENAI, um curso de Engenharia de Produção com uma de suas áreas de atuação voltada a projetos para couro e calçados.

É importante mencionar, ainda, que devido à própria organização dos empresários locais, é em Campina Grande que se encontra o Sindicato dos Calçadistas e a própria Federação das Indústrias do Estado da Paraíba, o que acaba dando maior força política ao arranjo local. Trata-se, portanto, de um verdadeiro "arranjo produtivo local de couro e calçados", conforme classificação feita em estudos por Cassiolato e Szapiro, (2002).

Metodologia

Considerando o critério de classificação de pesquisa proposto por Vergara (2007), a presente pesquisa é classificada como sendo descritiva, bibliográfica e de campo. Descritiva, pois visa analisar o perfil empreendedor dos empresários do ramo couro calçadista da cidade de Campina Grande. Bibliográfica, pois para a fundamentação teórica metodológica do trabalho serão utilizados materiais publicados em livros, artigos e redes eletrônicas. Considera-se ainda como sendo pesquisa de campo, pois dados primários serão coletados por meio de um questionário estruturado nas micro e pequenas empresas situadas em Campina Grande que atuam no setor couro calçadista.

\section{Referências Bibliográficas}

AZEVEDO, João Humberto de. Como iniciar uma empresa de sucesso. Rio de Janeiro: Qualitymark, 1992.

BARON, Robert A; SHANE A. Scott. Empreendedorismo: uma visão do processo; tradução All Tasks. São Paulo: Cengage Learning, 2011.

DEGEN, Ronald Jean. 0 empreendedor: empreender como opção de carreira. São Paulo: Pearson Prentice Hall, 2009.

DORNELAS, José Carlos Assis. 0 Processo Empreendedor. Disponível em < http://www.josedornelas.com.br/wpcontent/uploads/2008/02/empreendedorismo_capitulo_2.pdf>. Acesso em 10 de dezembro de 2010.

DORNELAS, José Carlos Assis. Transformando ideias em negócio. 2 ed - Rio de Janeiro: Elsevier, 2005.

FERREIRA, Aurélio B. H. O Dicionário da Língua Portuguesa. Curitiba: Positivo, 2000.

FILION, L.J. Visão e relações: elementos para um metamodelo da atividade empreendedora - International Small Business Journal, 1991 - Tradução de Costa, S.R.

GERBER, Michael E. Emprender fazendo a diferença. São Paulo: Saraiva, 2004.

HOUAISS, Antônio. Dicionário Houaiss da língua portuguesa. Rio de Janeiro: Objetiva, 2001.

MACHADO, Joana Paula et al. GEM: Empreendedorismo no Brasil: 2009. Curitiba: IBQP, 2010.

MAXIMIANO, Antônio Cesar Amaru. Administração para empreendedores: fundamentos da criação e da gestão de novos negócios. São Paulo: Pearson Prentice Hall, 2006.

MCCLELLAND, David. Characteristics of successful entrepreneurs. The Journal of Creative Behavior. v. 21, n. 3. p. 219-233, 1987.

MOUTINHO, Lúcia M. G. Ocupação da mão-de-obra em áreas de pobreza: recortes do setor de couros, calçados e afins da Paraíba. João Pessoa: CME/UFPB, 2003.

SCHUMPETER, J. The theory of economic development. Harvard University Press, 1949.

SEBRAE. Empretec PB. Disponível em < http://www.sebrae.com.br>. Acesso em 10 de dezembro de 2010. 
SILVA, Ricardo J. A.; SICSÚ, Abraham B.; CRISÓSTOMO, Antônio P. Identificação em processo de conhecimento - Estudo multicaso em APL de calçados de Campina Grande. Revista Gestão Industrial. ISSN 1808-0448 / v. 05, Edição Especial -GESTÃO DO CONHECIMENTO, p.189-215, 2009.

TIMMONS, J.A. New Venture Creation: Entrepreneurship for 21st Century. Chicago, IL: Irvin, 4th ed. 1994.

VERGARA, Sylvia Constant. Projetos e Relatórios de Pesquisa em Administração. 9 ed - São Paulo: Atlas, 2007. 